\title{
GESTÃO DEMOCRÁTICA E PARTICIPAÇÃO NA COMPOSIÇÃO DE CONSELHOS MUNICIPAIS DE EDUCAÇÃO NO PARANÁ
}

\author{
DEMOCRATIC MANAGEMENT AND PARTICPATION IN \\ MUNICIPAL EDUCATION COUNCILS IN PARANÁ
}

\section{GESTIÓN DEMOCRÁTICA Y PARTICIPACIÓN EN LA COMPOSICIÓN DE CONSEJOS MUNICIPALES DE EDUCACIÓN EN PARANÁ}

\begin{abstract}
Simone de Fátima Flach ${ }^{1}$
Universidade Estadual de Ponta Grossa (UEPG), Docente do Programa de Pós-graduação em Educação

\section{Kelly Letícia da Silva Sakata ${ }^{2}$}

Universidade Estadual do Centro-Oeste do Paraná (Unicentro), Pesquisadora do Grupo de Pesquisa em Estado, Política e Gestão em Educação
\end{abstract}

Resumo: A partir de pesquisa bibliográfica e análise documental, no presente texto tem-se como objetivo discutir o entendimento e a efetivação da gestão democrática em Conselhos Municipais de Educação no Paraná. Para tanto, apresentam-se discussões a respeito da democracia e as possibilidades de sua efetivação na educação, a forma como a composição e o funcionamento de Conselhos Municipais de Educação colaboram (ou não) para a efetivação do princípio constitucional, e como esta ocorre em um dos municípios pesquisados. Ao final, considera-se que tanto a composição quanto a atuação dos órgãos colegiados são contraditórias, pois, ao mesmo tempo que possibilitam a participação de diferentes segmentos sociais, sofrem interferências políticas locais, as quais limitam a atuação coletiva.

Palavras-chave: Gestão democrática. Participação. Conselho Municipal de Educação.

\footnotetext{
${ }^{1}$ Pós-doutora em Educação pela Universidade Tuiuti do Paraná; Doutora em Educação pela Universidade Federal de São Carlos; Mestre em Educação pela Universidade Federal do Paraná.

${ }^{2}$ Graduada em Pedagogia pela Universidade Estadual de Ponta Grossa; mestranda em Educação pela Universidade Estadual do Centro-Oeste do Paraná.
} 
Abstract: Based on the bibliographic research and the documental analysis, this text discusses the understanding and effectiveness in organize the municipal education councils in Paraná. For that present discussions about democracy end the possibility of effective it educational and works (or not) in the municipal educational councils for help the base of constitutional and how it occurs in one of the municipalities surveyed. In the end, shows that the compose and performance of collegiate bodies are contradictory, because in the sometime enables the different social segments participates and they suffer intervention in political, act that limit the collective performance.

Keywords: Democratic management. Participation. Municipal Education Councils.

Resumen: A partir de investigación bibliográfica y análisis documental, el presente texto tiene por objetivo discutir el entendimiento y la efectividad de la gestión democrática en Consejos Municipales de Educación en Paraná. Para ello presenta discusiones acerca de la democracia y las posibilidades de su efectividad en la educación, la forma en que la composición y el funcionamiento de los Consejos Municipales de Educación colaboran (o no) para la efectividad del principio constitucional y como ésta ocurre en uno de los municipios investigados. Al final, considera que tanto la composición como la actuación de los órganos colegiados son contradictorias, pues al mismo tiempo en que posibilitan la participación de diferentes segmentos sociales sufren interferencias políticas locales, las cuales limitan la actuación colectiva.

Palabras clave: Gestión democrática. Participación. Consejo Municipal de Educación.

\section{INTRODUÇÃO}

A discussão a respeito da gestão democrática na educação pública remete a posicionamentos divergentes sobre o entendimento de democracia e as formas pelas quais ele se materializa na atual forma de sociabilidade. O ideal democrático das sociedades modernas está profundamente atrelado a concepções de homem e sociedade e, para além de ser considerado um avanço, apresenta limites no atual modo de produção que rege a vida da humanidade, pois se fundamenta em uma perspectiva liberal, representativa e que pouco considera os interesses e necessidades da classe trabalhadora. Nessa perspectiva, desvelar os principais posicionamentos sobre democracia pode contribuir para o entendimento de sua efetivação nas ações político-educacionais.

O avanço democrático apontado pela Constituição da República de 1988 e pelos documentos legais e normativos posteriores, além alçar os municípios ao patamar de igualdade com os demais entes federados, reconhecendo sua autonomia para 
instituir sistemas municipais de ensino, ofereceu a abertura para a participação da sociedade na elaboração, acompanhamento e fiscalização das políticas públicas. No campo da educação essa abertura se mostrou presente na participação da sociedade em conselhos compostos por diferentes segmentos sociais (Conselho do Fundef e, posteriormente, do Fundeb, Conselhos Municipais de Educação e Conselhos Escolares), além da participação da comunidade escolar na elaboração do projeto político-pedagógico da escola.

No entanto, a gestão democrática da educação, assegurada nos documentos legais e normativos brasileiros, é interpretada e implementada de diferentes maneiras na realidade educacional, seja em nível de sistema de ensino, seja de escola, orientando os processos participativos da comunidade e como esta pode ou não colaborar nas decisões sobre as ações educacionais.

Consideramos que a gestão democrática pode se evidenciar em diferentes ações educacionais, podendo colaborar nas ações do poder público, na organização da escola e nos processos de ensino, sempre visando à melhoria da oferta da educação e dos resultados educacionais. Nesse sentido, indicamos que a gestão democrática, enquanto princípio orientador das ações político-educacionais, ocorre quando o poder público se abre para a participação e colaboração da sociedade, em especial a partir da sua atuação em conselhos que tenham funções deliberativas, propositivas e fiscalizadoras; quando a comunidade participa da escolha de dirigentes escolares, bem como do acompanhamento de seu trabalho; e, também, por meio da elaboração e prática do projeto político-pedagógico da escola.

Para tanto, a partir de pesquisa bibliográfica e análise documental, no texto apresentamos algumas discussões a respeito de democracia e as possibilidades de sua efetivação nos limites da sociedade capitalista. Em seguida, tendo como pressuposto o exercício da democracia no campo educacional, apresentamos como a gestão democrática, enquanto princípio basilar da educação nacional, está prevista nos documentos legais, indicamos os limites e possibilidades para a prática da gestão democrática em Conselhos Municipais de Educação do Estado do Paraná e analisamos o exercício democrático a partir das deliberações do Conselho Municipal de Educação de Ponta Grossa, PR, no período de 2003 a 2016.

Ao final, concluimos que a gestão democrática encontra guarida nos documentos legais, tanto nacionais quanto locais, mas que sua efetivação nos Conselhos Municipais de Educação é contraditória, em razão de que, ao mesmo tempo que amplia a participação de diferentes segmentos sociais, em casos específicos, há interferência do poder local na composição e na organização dos órgãos colegiados, limitando sua 
autonomia e suas funções propositiva e deliberativa. Assim, o princípio da gestão democrática, que deveria orientar o planejamento, o acompanhamento e a avaliação das políticas e propostas educacionais, ainda precisa constituir-se em meta a ser efetivada.

\section{PRESSUPOSTOS PARA A DEFESA DA DEMOCRACIA}

O entendimento e a possível efetivação do princípio da gestão democrática na educação implicam a compreensão a respeito da democracia que orienta as relações individuais e coletivas, bem como seus limites e possibilidades na atual forma de sociabilidade.

A sociedade capitalista, desde o seu surgimento, está assentada na exploração de uma classe sobre a outra. A manutenção e a ampliação da exploração necessitam de um conjunto de atividades "distintas do próprio processo de exploração, destinadas a assegurar a continuidade dessa relação de exploração.” (SAES, 1987, p. 11).

Esse conjunto de atividades que têm por objetivo assegurar a continuidade da exploração é materializado nas ações do Estado, principalmente por mecanismos que visam apaziguar os conflitos dando sustentabilidade à lógica capitalista. Entre esses mecanismos, podemos identificar o aparato legislativo que assegura a igualdade formal entre os indivíduos e a possibilidade de exercício da liberdade, esta entendida como a livre escolha para eleger seus representantes. Tais entendimentos dão visibilidade ao exercício de uma democracia que se vincula aos pressupostos liberais, ou seja, uma democracia formal e não real.

Para esclarecer a questão, nos ancoramos no pensamento de Saes (1987), que procura esclarecer seu significado ao longo da história, ressaltando seu vínculo ideológico. Para esse autor, o significado de democracia se difere ao longo da história humana e se vincula aos pressupostos que fundamentam o surgimento, o fortalecimento e a manutenção do Estado. Assim, o autor nomeia três tipos de democracia, as quais se desenvolveram ligadas à determinada forma de sociedade: democracias pré-burguesas, democracia burguesa e democracia socialista. As democracias pré-burguesas podem ser identificadas nas realidades em que, mesmo existindo a possibilidade de participação, essa não é oportunizada a todos os indivíduos, como ocorreu na Antiguidade (principalmente nas realidades grega e romana) e no Período Medieval. A democracia burguesa, nascida do movimento revolucionário burguês, pode ser identificada como aquela que, a partir da defesa de igualdade formal, possibilita a participação indistinta dos indivíduos no processo político. No entanto, essa forma de democracia oculta a desigualdade real entre os indivíduos em prol de uma igual- 
dade formal, assegurando o direito de votar e ser votado. Essa é a forma que orienta o exercício da democracia no seio da sociedade capitalista. E, por fim, por democracia socialista entendemos aquela que, fundamentada nos pressupostos marxistas, constitui-se em processo participativo e formativo dialético, no qual a igualdade, por ser real, possibilita maior participação de todos os indivíduos nos encaminhamentos políticos, sociais e econômicos.

Embora o termo democracia seja utilizado atualmente como possibilidade de participação do povo nas discussões e decisões políticas, é preciso compreender que a abertura para a participação ampla não ocorreu desde sempre, mas foi se moldando ao longo da história e das disputas por espaços coletivos para a participação. Nas democracias pré-burguesas, o modo de produção se fundamentava no escravismo ou no servilismo, excluindo escravos e servos (além das mulheres) dos processos participativos. Com o desenvolvimento do modo de produção capitalista e do consequente trabalho assalariado, a classe detentora dos meios de produção, visando ao seu fortalecimento enquanto classe e à direção política do Estado, apropriou-se e deu significado formal à democracia, conseguindo o apoio em troca de uma liberdade política formal e não real. Por isso, a partir da crítica da democracia burguesa, que se fundamenta na liberdade política formal, a democracia socialista ganha espaço nos debates como possibilidade de transformação social, visando a uma organização social pautada na relação entre iguais.

A democracia burguesa se fundamenta no pensamento da classe dominante na atual forma de sociabilidade, ou seja, tem como pressuposto a lógica capitalista, na qual a classe dominada, enquanto classe explorada, não tem oportunidade real de participação, em razão de se preocupar primeiro com as necessidades básicas de sobrevivência. Nesse sentido, a classe dominante, que detém o poder estatal, oferece à classe dominada uma igualdade formal, na qual esta tem a liberdade de expressar sua vontade nos limites impostos pelo aparato legal, ou seja, tem a oportunidade de escolher representantes. Assim, a democracia burguesa se fundamenta na representatividade, a qual sem mecanismos efetivos de controle fragiliza os interesses dos representados e possibilita a manutenção de interesses dominantes, pois, conforme já alertou Gramsci (2007, p. 83), “a racionalidade historicista do consenso numérico é sistematicamente falsificada pela influência da riqueza."

Em contraposição à democracia burguesa, convém expor os fundamentos da democracia pautada nos pressupostos socialistas, pois, conforme abordado por Saes (1987, p. 81), a democracia socialista abarca tanto o aspecto Estatal quanto as 
organizações de base, significando um modo de vida coletivo no qual há uma liberdade política real, exercida indistintamente por todos.

Nessa direção, Tonet $(2004,2009)$ explicita a relação entre o pensamento marxista e o sentido do conceito de democracia, fazendo distinção entre a democracia burguesa e a democracia socialista. Para tanto, indica que os pensadores marxistas interpretam a questão de diferentes formas e, para explicá-la, propõe em suas análises o estudo da natureza do pensamento de Marx em relação à democracia. Nesse sentido, indica a importância da Revolução Soviética de 1917, considerada um marco para o autor, pois aquele momento histórico “[...] recolocou na ordem do dia a perspectiva original marxiana, de caráter radicalmente crítico e revolucionário. Tratava-se de erradicar o capital e, com ele, o conjunto da sociabilidade burguesa e não de reformá-los." (TONET, 2009, p. 10).

Nessa perspectiva, objetivando a superação do modo de produção capitalista, a Revolução Soviética propôs um alinhamento radical aos escritos de Marx, almejando a superação do capitalismo e o aparecimento de uma nova ordem social, o socialismo. Contudo, o autor destaca que nada disso ocorreu, e o que emergiu, na verdade, foi uma “[...] brutal ditadura na qual nem sequer as objetivações democráticas-cidadãs burguesas tiveram a possibilidade de florescer.” (TONET, 2009, p. 10).

É importante destacar que, embora a Revolução Proletária ocorrida no início do século XX tenha sido deturpada em razão dos interesses burocráticos que guiaram o modo de pensar a política no contexto soviético, sua implantação fez emergir a discussão sobre a importância da participação popular, sem qualquer distinção de classe, nos encaminhamentos políticos. Em que pese a experiência e a derrocada de os socialismos reais mostrarem o quão difícil pode ser a realidade para a efetivação de uma sociedade sem divisão de classes, o contexto vivido fomentou a discussão sobre os limites da democracia burguesa, demonstrando como sua prática escamoteia uma verdadeira participação.

Por isso, ancorados no pensamento de Tonet (2004, 2009) e Saes (1987), defendemos um conceito para além da democracia burguesa, traduzido com a aquisição de direitos e liberdade plena ${ }^{3}$ para se tornar possível para todos os membros da sociedade. Para além, pontuamos que essa prática democrática somente poderá ser desenvolvida em outro tipo de sociabilidade, que supere o atual modo de produção

\footnotetext{
${ }^{3}$ Segundo Tonet (2004, 2009), a liberdade plena está intrinsecamente ligada à emancipação humana, ou seja, esse processo emancipatório universal somente é possível quando ocorrer a superação do capitalismo, e o trabalho associado se torne real, não havendo a exploração de uma classe sobre a outra.
} 
baseado na exploração do trabalho humano. Portanto, no seio da sociedade capitalista, a democracia possível estará sempre nos limites da representatividade.

Em que pese o reconhecimento dos limites da democracia na sociedade capitalista, há que se defender que outra democracia deve ser vista e defendida como possibilidade nos limites impostos pela realidade. Por isso, a classe trabalhadora precisa se apropriar da participação e fazer dela instrumento para as transformações necessárias na realidade.

Assim, defendemos uma democracia possível dentro dos limites da sociedade capitalista, de forma a emergir possíveis avanços quanto à participação da sociedade nas questões políticas educacionais. Saes (1987) auxilia na questão, resgatando o sentido democrático de um governo do povo que inclua, efetivamente, toda a população.

Dessa forma, a democracia está além de uma simples forma política, pois apenas existirá, de fato, com a superação da sociabilidade capitalista, na medida em que resgata o conceito de liberdade e o amplia no sentido de emancipação humana. É a significativa participação e envolvimento de todas as pessoas que constitui a democracia. Nos limites da sociedade capitalista, a possibilidade de participação democrática, em especial no campo educacional, ocorre no exercício de participação em instâncias colegiadas, que tenham funções deliberativas, propositivas e fiscalizadoras.

A participação em instâncias colegiadas é sempre complexa e contraditória, pois confronta interesses de grupos diferentes. No entanto, ela cria condições para a superação de defesas corporativas e colabora para o desenvolvimento de uma consciência coletiva, pois, conforme já nos ensinou Gramsci (2007, p. 333, grifo do autor),

Uma consciência coletiva, ou seja, um organismo vivo só se forma depois que a multiplicidade se unifica através do atrito dos indivíduos: e não se pode dizer que o "silêncio" não seja multiplicidade. Uma orquestra que ensaia cada instrumento por sua conta, dá a impressão da mais horrível cacofonia; porém, estes ensaios são a condição para que a orquestra viva como um só "instrumento".

Nesse sentido, o processo participativo é formativo ao expressar a correlação de forças presentes na realidade, pois ao confrontar diferentes posicionamentos fomenta as discussões e colabora em decisões e compromissos coletivos.

Para Catani e Gutierrez (1998, p. 61), além dessas complexidades, existem duas dificuldades ao estudar a participação: a consciência individual dos sujeitos e a associação de que a participação efetiva e com qualidade está atrelada à quantidade dos sujeitos participantes.

Consideramos que a consciência dos sujeitos é adquirida na práxis e no processo participativo, na coletividade e no pensamento acerca dos resultados de suas 
escolhas, ou seja, "[...] participar consiste em ajudar a construir comunicativamente o consenso quanto a um plano de ação coletivo." (CATANI; GUTIERREZ, 1998, p. 62). Dessa forma, ocorreria a superação das diferenças individuais, na medida em que todos poderiam participar e discutir as melhores soluções encontradas pelo grupo, superando um consenso passivo ${ }^{4}$ e assumindo uma forma crítica por meio do consenso ativo, ${ }^{5}$ pois a questão vital não é "o consenso passivo e indireto, mas o consenso ativo e direto, ou seja, a participação dos indivíduos, ainda que isto provoque uma aparência de desagregação e tumulto.” (GRAMSCI, 2007, p. 333).

Desse modo, Bordenave (1983, p. 30) indica, ainda, a existência de graus e níveis de participação, os quais estão atrelados ao nível de controle dos dirigentes dos grupos e às decisões que os membros têm acesso no processo participativo, ou seja: que tipo de participação é concedido para a maioria? Quais questões (primordiais ou secundárias) trariam mudanças efetivas na vida dos envolvidos? Sobre esses questionamentos indicamos que a democracia participativa "[...] promove a subida da população a níveis cada vez mais elevados de participação decisória, acabando com a divisão de funções entre os que planejam e decidem lá em cima e os que executam e sofrem as consequências das decisões cá embaixo.” (BORDENAVE, 1983, p. 34).

O exercício da democracia promove o desenvolvimento da consciência coletiva, pois envolve todos os membros das organizações. Por isso, a defesa da gestão democrática na educação ganha força e adquire relevância na conjuntura política brasileira após o Período Ditatorial Militar. Por meio dos canais de gestão democrática, criados e permitidos pela legislação brasileira, cada membro contribui tanto no planejamento quanto nas ações, deixando de ser passivo e assumindo, assim, as responsabilidades nas decisões. Nessa perspectiva, a gestão democrática pode ser indicada como uma das possibilidades de vivência da democracia, mesmo que nos limites do capitalismo.

\section{ASPECTOS LEGAIS PARA A GESTÃO DEMOCRÁTICA DA EDUCAÇÃO BRASILEIRA}

As determinações legais e normativas a respeito do princípio da gestão democrática para a educação brasileira estão vinculadas aos aspectos sociais, políticos e econômicos que norteiam a sociedade brasileira a partir da reabertura política

\footnotetext{
${ }^{4}$ Segundo Gramsci (2007), o consenso passivo é aquele que ocorre por meio de uma imposição hierárquica, de cima para baixo, restando aos sujeitos apenas cumprir o que foi predeterminado por grupo específico, sem debate ampliado de ideias.

${ }^{5} \mathrm{O}$ consenso ativo, segundo o pensador sardo, é aquele criado a partir de um debate amplo de ideias entre os sujeitos de forma a alcançar um convencimento coletivo em relação ao que foi discutido.
} 
ocorrida em meados dos anos 1980. O Período Ditatorial Militar, de 1964 a 1985, foi marcado por um eficaz aparato político-ideológico que reprimiu a participação social nos processos decisórios. No entanto, o seu enfraquecimento possibilitou a retomada das reivindicações participativas por diversos segmentos sociais, contribuindo para a construção de novo aparato constitucional.

A Constituição da República de 1988 pode ser apontada como marco regulatório para os processos participativos que se evidenciaram nos anos posteriores. Não é sem sentido que o referido Documento constitucional expresse em seu art. $1^{\circ}$ que a República Federativa do Brasil "constitui-se em Estado Democrático de Direito" e que, conforme parágrafo único, "todo poder emana do povo.” (BRASIL, 1988, p. 3).

Segundo Silva (1988), o conceito de Estado democrático de direito adotado pela Constituição da República incorpora princípios do Estado de direito e do Estado democrático. $\mathrm{O}$ primeiro, tipicamente liberal, visa à garantia de direitos burgueses sob o império da lei, divisão de poderes e proteção dos direitos individuais. O segundo, de vinculação socialista, está assentado no princípio da soberania popular enquanto base de uma sociedade democrática que "instaure um processo de efetiva incorporação de todo o povo nos mecanismos do controle das decisões, e de sua real participação nos rendimentos da produção." (SILVA, 1988, p. 21). No entanto, o autor alerta que a Constituição de 1988 "não chegou a estruturar um Estado democrático de Direito de conteúdo socialista” (SILVA, 1988, p. 22), mas podemos inferir que, nos limites do direito, possibilitou práticas reivindicatórias assentadas em processos participativos.

Portanto, sob os ditames da Constituição da República de 1988, a participação pode ser exercida por meio do acompanhamento das políticas públicas. Entretanto, a participação, em geral, ocorre pela forma representativa, pois a forma direta de participação do cidadão ocorre apenas no exercício do direito ao voto para eleger seus representantes. Nesse sentido, a participação é apenas formal, não real.

Em relação à educação, a Constituição da República inclui entre seus princípios, conforme art. 206, VII, a "gestão democrática do ensino público" (BRASIL, 1988), instituindo a participação na gestão de escolas e sistemas de ensino. Na esteira desse Dispositivo Constitucional, a Lei de Diretrizes e Bases da Educação Nacional, Lei n. 9.394/96, também dá forma à gestão democrática quando prevê:

Art. $3^{\circ}$. $\mathrm{O}$ ensino será ministrado com base nos seguintes princípios:

$[\ldots]$

VIII - gestão democrática do ensino público, na forma desta

Lei e da legislação dos sistemas de ensino;

$[\ldots]$ 
Art. 14. Os sistemas de ensino definirão as normas da gestão democrática do ensino público na educação básica, de acordo com as suas peculiaridades e conforme os seguintes princípios: I - participação dos profissionais da educação na elaboração do projeto pedagógico da escola;

II - participação das comunidades escolar e local em conselhos escolares ou equivalentes.

$[\ldots]$

Art. 56. As instituições públicas de educação superior obedecerão ao princípio da gestão democrática, assegurada a existência de órgãos colegiados deliberativos, de que participarão os segmentos da comunidade institucional, local e regional. (BRASIL, 1996, grifo nosso).

A gestão democrática prevista pode ser exercida nos limites da "legislação dos sistemas de ensino", a qual pode, ou não, indicar um processo democrático amplo, com participação de um número significativo de indivíduos, mesmo que sob a tutela da representatividade por meio da participação em "Conselhos". Nessa perspectiva, a gestão democrática envolve diferentes segmentos sociais nas decisões educacionais, organizando a escola "quanto aos aspectos políticos, administrativos, financeiros, tecnológicos, culturais, artísticos e pedagógicos, com a finalidade de dar transparência às suas ações e atos.” (BRASIL, 2006, p. 24). Em nível de sistemas de ensino, a gestão democrática implica o "ordenamento normativo e jurídico e a vinculação de instituições sociais por meio de diretrizes comuns." (BRASIL, 2006, p. 24).

Na prática, por força das exigências legais, na gestão escolar e nos sistemas de ensino a gestão democrática tem se efetivado por meio da atuação da comunidade escolar ou de diferentes segmentos sociais em Conselhos Escolares, Conselhos de Acompanhamento Social (como Conselhos do Fundeb e Conselhos de Alimentação Escolar) ou em Conselhos Municipais de Educação.

Para além dos dispositivos constitucionais e da Lei de Diretrizes e Bases da Educação Nacional, a questão também está presente nas estratégias da Meta 19 do Plano Nacional de Educação, Lei n. 13.005/2014, quando estabelece a ampliação de programas de apoio e formação de conselheiros (estratégia 19.2), incentivo à constituição de fóruns permanentes de educação (estratégia 19.3) e o estímulo à constituição e fortalecimento de "conselhos escolares e conselhos municipais de educação como instrumentos de participação e fiscalização na gestão escolar e educacional.” (BRASIL, 2014). Essas previsões indicam o fortalecimento de processos democráticos na busca de uma educação de qualidade.

No entanto, Marques (2014, p. 466) alerta que 
A gestão democrática da educação requer mais do que simples mudanças nas estruturas organizacionais; requer mudança de paradigmas que fundamentam a construção de uma proposta educacional e o desenvolvimento de uma gestão diferente da que hoje é vivenciada. Ela precisa estar para além dos padrões vigentes, comumente desenvolvidos pelas organizações democráticas.

Na perspectiva apontada pela autora, a gestão democrática é uma possibilidade de rompimento com as formas hierarquizadas e burocráticas historicamente presentes na condução das políticas públicas brasileiras. No entanto, a gestão democrática precisa ser entendida como processo, que se faz e se transforma continua e cotidianamente.

A prática participativa em Conselhos de Educação pode indicar como a democracia é vivida nos contextos locais. Por isso, analisamos como o princípio da gestão democrática se faz presente na Constituição e nos Conselhos Municipais de Ensino de municípios paranaenses que já instituíram seus Sistemas Municipais de Ensino para, em seguida, analisar como ocorre o processo deliberativo no Conselho Municipal de Educação de Ponta Grossa.

\section{LIMITES E POSSIBILIDADES PARA A GESTÃO DEMOCRÁTICA EM CONSELHOS MUNICIPAIS DE EDUCAÇÃO}

A opção em analisar Conselhos Municipais de Educação em municípios que já instituíram Sistemas de Ensino se justifica em razão de que tais municípios romperam as amarras hierárquicas dos Sistemas Estaduais de Ensino, tornando-se autônomos, principalmente para normatizar as questões educacionais específicas de sua realidade.

O art. 11 da Lei n. 9.394/96 autoriza que os municípios criem “[...] normas complementares para seu sistema de ensino." (BRASIL, 1996, p. 27835). No entanto, para que a autorização legal assuma efetividade prática, é necessária a existência de um órgão normativo que se materializa na existência e no funcionamento de um Conselho Municipal de Educação deliberativo e autônomo, fundamentado em práticas democráticas. Por isso, a gestão democrática é o eixo fundamental para o funcionamento de tais colegiados.

Atualmente, no Estado do Paraná, dos 399 municípios apenas 16 já instituíram legalmente seus sistemas de ensino e têm Conselhos Municipais de Educação com funções normativas. São eles: Araucária, Cascavel, Chopinzinho, Curitiba, 
Guarapuava, Ibiporã, Iguatu, Londrina, Palmeira, Paranaguá, Pinhais, Ponta Grossa, Sarandi, São José dos Pinhais, Telêmaco Borba e Toledo. A composição e organização desses colegiados pode indicar como a democracia (representativa) é entendida nos contextos locais, podendo representar a ampliação do debate a respeito dos assuntos educacionais locais ou se caracterizar como órgão legitimador das ações governamentais, constituindo-se como mero braço do Estado, sem pautar suas ações pelas necessidades de seus representados. Nesse sentido, a democracia representativa que fundamenta o exercício formal da participação se mostra ainda mais viciada por se distanciar de sua base de sustentação.

A esse respeito, convém apresentar como o sistema representativo está presente na composição dos Conselhos de Educação dos municípios integrantes da análise. De maneira geral, a composição dos Conselhos tem membros de diferentes segmentos da sociedade, como: representantes do governo municipal, dos servidores municipais, de pais ou responsáveis, de alunos, de instituições de ensino particulares tanto da educação básica quanto superior, de outros conselhos sociais, entre outros. No entanto, alguns casos chamam a atenção: em Guarapuava os conselheiros são indicados por lista tríplice, sendo de livre escolha do prefeito o indicado para nomeação (tal prática se mostra vinculada aos interesses político-partidários que sustentam determinados grupos no poder local). Em São José dos Pinhais, a presidência do órgão é de livre indicação do prefeito, e em Chopinzinho, é exercício nato do Secretário Municipal de Educação. Tais práticas indicam interferência na autonomia do órgão e, consequentemente, no exercício democrático para o acompanhamento das políticas educacionais municipais.

Outra questão que se mostra relevante na composição dos Conselhos Municipais de Educação é a falta de formação específica para o desempenho das funções, fato que colabora no direcionamento das discussões conforme os interesses governamentais, sem possibilitar profundos debates a respeito da educação sob a responsabilidade dos municípios, prejudicando funções do órgão, em especial aquelas direcionadas às proposições conforme as necessidades locais e fiscalizações das ações governamentais, tão necessárias para o desenvolvimento da democracia com a consequente efetivação da autonomia.

No caso específico do Município de Ponta Grossa, o Conselho Municipal é o mais numeroso de todo o Estado, contando com 21 membros, os quais representam diferentes segmentos: quatro representantes da Secretaria Municipal de Educação; um representante do Núcleo Regional de Educação; três representantes de instituições públicas de ensino superior; um representante de instituição privada de ensino superior; 
um representante da Federação da Indústria do Estado do Paraná (FIEP); dois representantes da rede privada de ensino, sendo um do ensino fundamental e outro da educação infantil; um representante do Sindicato dos Servidores Municipais; um representante do Conselho Municipal dos Direitos da Criança e do Adolescente (CMDCA-PG); um representante do Conselho Tutelar; um representante dos diretores das escolas municipais ou centros municipais de educação infantil; um representante da União das Associações de Moradores (UAMPG); um representante do quadro próprio do magistério estadual; um representante de pais de alunos matriculados na rede municipal de ensino; um representante das escolas ou centros de educação especial; e um representante do Conselho Municipal dos Direitos das Pessoas Portadoras de Deficiência (PONTA GROSSA, 2011). Entretanto, tal composição não assegura a efetiva participação equitativa de todos os membros em razão de que a elaboração de documentos orientadores e normativos envolve, senão os mesmos, poucos segmentos representados, conforme evidenciado na análise das deliberações emitidas pelo referido Conselho.

Em uma análise preliminar, a composição do referido Conselho Municipal de Educação indica certa paridade entre membros representantes do poder público e organizações da sociedade, sendo esta de maior representatividade do que aquele. No entanto, ao analisar os setores envolvidos no processo deliberativo, essa situação não se confirma, conforme pode ser observado no Quadro 1.

Quadro 1 - Participação de representantes na elaboração e/ou discussão de deliberações do Conselho Municipal de Educação de Ponta Grossa, PR (2003-2016)

\begin{tabular}{|c|c|c|c|c|c|c|c|c|c|c|c|c|c|c|c|c|}
\hline \multirow[b]{2}{*}{$\stackrel{\circ}{\stackrel{2}{4}}$} & \multirow[b]{2}{*}{ 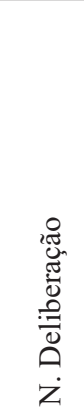 } & \multicolumn{15}{|c|}{ Segmentos representados / Relatores } \\
\hline & & $\sum_{n}^{1}$ & 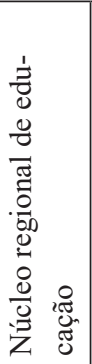 & 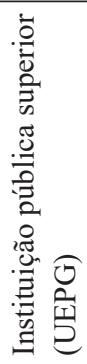 & 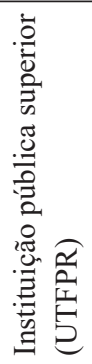 & 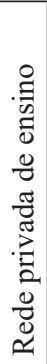 & 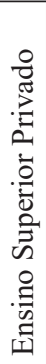 & $\frac{0}{\mid \underline{|r|}}$ & 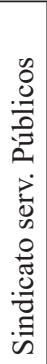 & $\sum_{\circlearrowright}^{\mathbb{U}}$ & 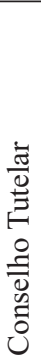 & 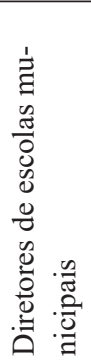 & 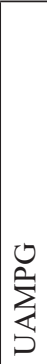 & 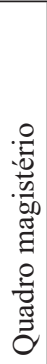 & 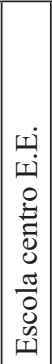 & $\begin{array}{l}\frac{8}{0} \\
\frac{0}{2} \\
0 \\
\frac{0}{0} \\
0 \\
0 \\
0 \\
0\end{array}$ \\
\hline \multirow{6}{*}{2004} & $01 / 04$ & $\mathrm{x}$ & & $\mathrm{x}$ & & $\mathrm{x}$ & & & & & & & & & & \\
\hline & $02 / 04$ & $\mathrm{x}$ & & $\mathrm{x}$ & & $\mathrm{x}$ & & & & & & & & & & \\
\hline & $03 / 04$ & $\mathrm{x}$ & & $\mathrm{x}$ & & $\mathrm{x}$ & & & & & & & $\mathrm{x}$ & & & \\
\hline & $04 / 04$ & $\mathrm{x}$ & & $\mathrm{x}$ & & $\mathrm{x}$ & & & & & & & & & & \\
\hline & $07 / 04$ & $\mathrm{x}$ & & $\mathrm{x}$ & & $\mathrm{x}$ & & & & & & & & & & \\
\hline & $08 / 04$ & $\mathrm{x}$ & & $\mathrm{x}$ & & $\mathrm{x}$ & & & & & & & & & & \\
\hline \multirow{2}{*}{2005} & $01 / 05$ & $\mathrm{x}$ & & $\mathrm{x}$ & & $\mathrm{x}$ & & & & & & $\mathrm{x}$ & $\mathrm{x}$ & & & \\
\hline & $02 / 05$ & $\mathrm{x}$ & & $\mathrm{x}$ & & $\mathrm{x}$ & & & & & & $\mathrm{x}$ & $\mathrm{x}$ & & & \\
\hline
\end{tabular}




\begin{tabular}{|c|c|c|c|c|c|c|c|c|c|c|c|c|c|c|c|c|}
\hline \multirow{2}{*}{2006} & $01 / 06$ & $\mathrm{x}$ & & $\mathrm{x}$ & & $\mathrm{x}$ & & & & & & & & & & \\
\hline & $02 / 06$ & $\mathrm{x}$ & & & $\mathrm{x}$ & $\mathrm{x}$ & & & & & & $\mathrm{x}$ & & & & \\
\hline 2007 & $01 / 07$ & $\mathrm{x}$ & & $\mathrm{x}$ & & $\mathrm{x}$ & & & & & & & & & & \\
\hline 2009 & $01 / 09$ & $\mathrm{x}$ & & & & & $\mathrm{x}$ & & & $\mathrm{x}$ & & $\mathrm{x}$ & & & & \\
\hline 2010 & $01 / 10$ & $\mathrm{x}$ & & & & & $\mathrm{x}$ & & & $\mathrm{x}$ & & & & & & \\
\hline \multirow{2}{*}{2011} & $01 / 11$ & $\mathrm{x}$ & & & & & $\mathrm{x}$ & & & $\mathrm{x}$ & & & & & & \\
\hline & $02 / 11$ & & & & & & & & & & & & & & & $\mathrm{x}$ \\
\hline \multirow{5}{*}{2012} & $01 / 12$ & & & & & & & & & & & & & & & $\mathrm{x}$ \\
\hline & $02 / 12$ & $\mathrm{x}$ & & $\mathrm{x}$ & $\mathrm{x}$ & & $\mathrm{x}$ & & & & & $\mathrm{x}$ & $\mathrm{x}$ & $\mathrm{x}$ & & \\
\hline & $03 / 12$ & $\mathrm{x}$ & & $\mathrm{x}$ & & $\mathrm{x}$ & $\mathrm{x}$ & & $\mathrm{x}$ & $\mathrm{x}$ & $\mathrm{x}$ & & & & $x$ & \\
\hline & $04 / 12$ & & & & & & & & & & & & & & & $\mathrm{x}$ \\
\hline & $05 / 12$ & $\mathrm{x}$ & & $\mathrm{x}$ & $\mathrm{x}$ & & $\mathrm{x}$ & & & & & $\mathrm{x}$ & $\mathrm{x}$ & $\mathrm{x}$ & & \\
\hline \multirow{3}{*}{2013} & $01 / 13$ & $\mathrm{x}$ & $\mathrm{x}$ & $\mathrm{x}$ & $\mathrm{x}$ & $\mathrm{x}$ & $\mathrm{x}$ & $\mathrm{x}$ & $\mathrm{x}$ & & $\mathrm{x}$ & $\mathrm{x}$ & $\mathrm{x}$ & & & \\
\hline & $02 / 13$ & $\mathrm{x}$ & $\mathrm{x}$ & $\mathrm{x}$ & & & $\mathrm{x}$ & & & & & $\mathrm{x}$ & $\mathrm{x}$ & & & \\
\hline & $03 / 13$ & & & & & & & & & & & & & & & $\mathrm{x}$ \\
\hline \multirow{2}{*}{2014} & $01 / 14$ & $\mathrm{x}$ & $\mathrm{x}$ & $\mathrm{x}$ & & & $\mathrm{x}$ & & & & & $\mathrm{x}$ & $\mathrm{x}$ & & & \\
\hline & $02 / 14$ & & & & & & & & & & & & & & & $\mathrm{x}$ \\
\hline \multirow{2}{*}{2015} & $01 / 15$ & $\mathrm{x}$ & & $\mathrm{x}$ & & & & & $\mathrm{x}$ & $\mathrm{x}$ & & & & $\mathrm{x}$ & & \\
\hline & $02 / 15$ & & & & & & & & & & & & & & & $\mathrm{x}$ \\
\hline \multirow{2}{*}{2016} & $01 / 16$ & & & & & & & & & & & & & & & $\mathrm{x}$ \\
\hline & $02 / 16$ & & & & & & & & & & & & & & & $\mathrm{x}$ \\
\hline
\end{tabular}

Fonte: os autores.

Nota: Optamos por levantar os segmentos representados para não identificar individualmente os membros do CME.

$\mathrm{O}$ ano 2004 indica que quatro segmentos, dos 15 que compõem o CME, elaboraram e discutiram os assuntos em pauta nas deliberações, e, de forma isolada, houve uma média de três segmentos por assunto discutido.

É importante destacar que 2004 foi o último ano da gestão municipal sob a responsabilidade do Partido dos Trabalhadores, o qual tinha na época uma proposta de instituir um debate com a comunidade sobre as políticas em curso, questão que pode ser apontada como contraditória em razão de não ter sido fomentada a participação dos diversos segmentos nas discussões ocorridas e consequente elaboração das deliberações, evidenciando a fragilidade dos gestores públicos a respeito dos fundamentos da gestão democrática. Entendemos que esse fato possa ter ocorrido em razão da urgência em corrigir lacunas na efetivação da implantação do Ensino Fundamental de nove anos e a consequente correção da documentação escolar em razão de matrículas não autorizadas pelo Conselho Estadual de Educação quando o Município ainda não tinha instituído Sistema Próprio de Ensino. A esse respeito, convém esclarecer que uma das razões para a criação do Sistema Municipal de Ensino com a devida alteração das funções do Conselho Municipal de Educação foi a negativa do Conselho Esta- 
dual de Educação do Paraná para a matrícula antecipada de crianças com seis anos incompletos no ensino fundamental no ano 2001. A partir desse impasse, o Sistema Municipal foi criado em 2002, e o Conselho Municipal de Educação teve suas funções alteradas em 2003.

No período posterior, de 2005 a 2007, houve ampliação dos segmentos que participaram do processo de discussão e elaboração dos documentos normativos relativos ao estudo dos assuntos em pauta nas deliberações. Embora seja evidente a ampliação de segmentos participantes, os assuntos de maior relevância estiveram sob a responsabilidade da SME, da Rede Particular de Ensino Superior e da UEPG. Assim, os assuntos discutidos nesse período ficaram restritos a um pequeno grupo, e, de forma isolada, houve a participação de quatro segmentos em média por assunto deliberado (Deliberações n. 01/05, 02/05, 01/06, 02/06 e 01/07).

No período de 2009 a 2012, 12 segmentos se fizeram presentes nas deliberações. No entanto, a participação em assuntos que tinham maior impacto na educação municipal foi restrita, em virtude de que se limitaram a uma média de cinco segmentos (Deliberações n. 01/09, 01/10, 01/11, 02/12, 03/12 e 05/12).

De 2013 a 2016, vemos que 13 segmentos participaram dos assuntos deliberados no CME, em média participaram sete segmentos por assunto discutido (Deliberações n. 01/13, 02/13, 01/14 e 01/15). Em todo o período analisado (2004-2016) os assuntos que tiveram a participação de todos os membros foram aqueles relativos ao calendário de reuniões, em razão de que consta nos documentos que o Conselho Pleno $^{6}$ foi responsável pelas elaborações (Deliberações n. 02/11, 01/12, 04/12, 03/13, 02/14, 02/15, 01/16 e 02/16).

A representação nas deliberações, de forma global, ficou restrita a um pequeno grupo: à SME (em todos os períodos), à Rede Particular de Ensino Fundamental, à Rede Particular de Ensino Superior ${ }^{7}$ e à UEPG. De acordo com a análise dos documentos, não houve uma participação efetiva de todos os segmentos nas discussões realizadas; quando ocorreu, esta foi relativa à discussão e aprovação de cronogramas e calendário de reuniões. Dessa forma, a participação em assuntos relativos à educação municipal é frustrada para setores não afetos diretamente à temática educacional, corroborando a ideia de que as decisões devem ser tomadas pelos grupos que detêm o controle cultural, político e econômico. Essa lógica não contribui para o desenvolvi-

\footnotetext{
${ }^{6}$ O Conselho Pleno é composto por todos os membros do Conselho Municipal de Educação.

7 Embora não seja objeto da discussão aqui realizada, convém alertar que os segmentos vinculados à iniciativa privada (escolas particulares e ensino superior particular) tiveram em todo o período, de forma alternada, a mesma pessoa como representante. Esse fato pode indicar demarcação da influência de caráter personalíssimo do setor privado na condução da política educacional local.
} 
mento de uma consciência coletiva sobre os encaminhamentos políticos para o setor educacional em conformidade com as necessidades sociais.

A esse respeito, Bordenave (1983, p. 12) chama a atenção para a importância da participação ampliada.

Do ponto de vista dos setores progressistas, a participação facilita o crescimento da consciência crítica da população, fortalece seu poder de reivindicação e a prepara para adquirir mais poder na sociedade. Além disso, por meio da participação, conseguem-se resolver problemas que ao indivíduo parecem insolúveis se contar só com suas próprias forças, tais como a construção de uma estrada, ou uma ponte, ou a recuperação de delinquentes juvenis numa comunidade marginal.

Partindo do pressuposto de que a participação é intrínseca a uma gestão democrática, enquanto propulsora do conhecimento individual e de consciência coletiva, e que o CME é o órgão colegiado que representa essa possibilidade histórica no campo educacional, entendemos que a condução das discussões e a elaboração de documentos normativos exarados do órgão analisado ficou aquém de um amplo processo participativo. Os assuntos foram estudados e deliberados por uma pequena parcela de seus membros, o que significa que $19,5 \%$ da representatividade total participam de forma efetiva nas discussões e na elaboração de documentos.

O caso analisado indica o quão frágil pode ser a efetivação da gestão democrática no contexto local, mesmo no interior de órgão colegiado organizado para e com a participação de diferentes segmentos sociais.

Ainda, a composição de Conselhos Municipais de Educação em diferentes municípios paranaenses mostra como a participação popular é assegurada (ou não) pela legislação local, indicando que há um longo caminho a ser percorrido para que o exercício da democracia deixe de ser formal e se torne real. Somente assim, na e pela práxis, a vivência democrática se fortalece e colabora para o alcance de objetivos coletivos.

\section{CONSIDERAÇÕES FINAIS}

O princípio da gestão democrática indica a participação como fundamental para a sua concretização. Nesse sentido, a participação ampla ultrapassa os interesses individuais e atinge os coletivos. Por isso, a participação é entendida como um processo que não se esgota no momento do exercício da escolha ou da decisão, mas se torna amplo ao propiciar o desenvolvimento individual e coletivo visando aos objetivos da sociedade como um todo e não de um pequeno grupo. 
Em que pese os Conselhos Municipais de Educação, enquanto órgãos colegiados, serem constituídos como possibilidade de exercício democrático, suas composições, seus membros e o modo como se organizam podem ser considerados como síntese da realidade à qual estão vinculados. Dessa forma, as práticas democráticas são resultantes do modo de organização social e, por isso mesmo, são frágeis, contraditórias e indicam a necessidade do debate a respeito da importância da participação enquanto processo formativo, individual e coletivo.

A composição dos Conselhos Municipais de Educação analisados indicam para a participação de diferentes segmentos sociais, fato que pode colaborar para a ampliação do debate sobre as políticas públicas para o setor. No entanto, em alguns casos (Guarapuava, Pinhais e Chopinzinho) há dispositivo legal para a interferência do gestor público tanto na indicação de membros quanto na presidência do órgão, o que pode induzir um controle conforme os interesses do grupo que exerce o poder local ou mesmo indução de legitimação das ações de determinado período gestionário.

Nessa perspectiva, e ao procurar desvendar a realidade concreta, podemos perceber que esta é resultado de um conjunto de determinações que ora mostram, ora escondem os reais interesses que orientam a gestão democrática em órgãos colegiados.

No caso pontagrossense, constatamos que, embora existam dispositivos sobre gestão democrática nos documentos legais que regem o referido CME, e que ao longo de sua história houve a indicação de ampliação da participação dos segmentos envolvidos, as decisões deliberadas ficaram sob a responsabilidade de um pequeno grupo. Tal prática evidencia que a participação da sociedade organizada é fragilizada e que, consequentemente, a gestão democrática precisa percorrer um longo caminho para se efetivar enquanto princípio basilar dos encaminhamentos político-educacionais.

Os assuntos deliberados indicam uma tendência de discussão referente a pautas que emergem da Secretaria Municipal da Educação. Há indicativos nos documentos analisados de que o CME de Ponta Grossa não promove espaços para o debate a respeito de assuntos advindos de segmentos não vinculados ao poder público, ou seja, as deliberações ficam à mercê dos interesses e compromissos do gestor público municipal, de forma a neutralizar as funções normativas e propositivas do órgão, tornando-o legitimador das propostas governamentais.

A realidade da composição dos Conselhos Municipais de Educação em municípios que instituíram Sistemas Próprios de Ensino demonstra que a ampliação da participação da sociedade nas políticas municipais é fato, mas que é contraditória, em virtude de que ao mesmo tempo que amplia a participação a fragiliza em razão do controle governamental na indicação de membros. Ainda, no caso de Ponta Grossa, as 
discussões e deliberações não evidenciaram ações propositivas; suas deliberações indicam que poucas representações se envolvem efetivamente em estudos e discussões a respeito das demandas educacionais.

Nesse contexto, concluimos que o princípio da gestão democrática, que deveria orientar o planejamento, o acompanhamento e a avaliação das políticas e propostas educacionais, ainda precisa se constituir em meta a ser efetivada.

Portanto, a questão aqui apresentada não encerra a discussão, mas aponta para a necessidade de outras análises que possam auxiliar na compreensão da realidade e, então, colaborar para que a gestão democrática deixe de ser, enquanto princípio basilar da educação nacional, apenas previsão e se torne real, favorecendo o envolvimento coletivo em prol de uma educação socialmente referenciada.

\section{REFERÊNCIAS}

BORDENAVE, J. E. D. O que é participação? 7. ed. São Paulo: Brasiliense, 1983.

BRASIL. Constituição. República Federativa do Brasil de 1988. Brasília, DF: Senado Federal, 1988.

BRASIL. Lei n. 9.394, de 20 de dezembro de 1996. Estabelece as diretrizes e bases da educação nacional. Diário Oficial da União, Brasília, DF, 23 dez. 1996.

BRASIL. Lei n. 13.005, de 25 de junho de 2014. Aprova o Plano Nacional de Educação - PNE e dá outras providências. Diário Oficial da União, Brasília, DF, 26 jun. 2014.

BRASIL. Ministério da Educação. Secretaria de Educação Básica. Gestão da educação escolar. Brasília, DF: Ed. UnB/CEAD, 2006.

CATANI, A. M.; GUTIERREZ, G. L. Participação e gestão escolar: conceitos e potencialidade. In: FERREIRA, N. S. C. (Org.). Gestão democrática da educação: atuais tendências, novos desafios. São Paulo: Cortez, 1998. p. 59-75.

GRAMSCI, A. Cadernos do Cárcere. 3. ed. Rio de Janeiro: Civilização Brasileira, 2007. $3 \mathrm{v}$.

MARQUES, L. R. Gestão Democrática da educação: projetos em disputa. Retratos da Escola, v. 8, n. 15, p. 463-472, jul./dez. 2014. 
PONTA GROSSA. Lei Municipal n. 10.593, de 20 de junho de 2011. Dispõe sobre o Conselho Municipal de Educação. Disponível em: <https://leismunicipais. com.br/a/pr/p/ponta-grossa/lei-ordinaria/2011/1059/10593/lei-ordinaria-n-10593-2011-dispoe-sobre-o-conselho-municipal-de-educacao>. Acesso em: 29 set. 2016.

SAES, D. Democracia. São Paulo: Ática, 1987.

SILVA, J. A. O estado democrático de direito. Revista de Direito Administrativo, Rio de Janeiro, n. 173, p. 15-34, jul./set. 1988. Disponível em $<$ http://bibliotecadigital.fgv.br/ojs/index.php/rda/article/viewFile/45920/44126>. Acesso em: 03 jul. 2017.

TONET, I. Marxismo e democracia. In: BORGES, L. F. B.; MAZZUCO, N. G. (Org.). Democracia e políticas sociais na América Latina. São Paulo: Xamã, 2009. p. 9-21.

TONET, I. Socialismo e democracia. In: TONET, I. (Org.). Democracia ou liberdade? 2. ed. Maceió: Edufal, 2004. p. 73-82.

Recebido em: 06 de agosto de 2017 Aceito em: 09 de outubro de 2017

Endereço para correspondência: Av. General Carlos Cavalcanti, 4748, 84030-900, Ponta Grossa, Paraná, Brasil; eflach@uol.com.br 
